HEROES AND MARTYRS OF QUALITY AND SAFETY

\title{
Florence Nightingale gets no respect: as a statistician that is
}

\author{
D Neuhauser
}

Qual Saf Health Care 2003;12:317

$\mathrm{F}$ orence Nightingale (1820-1910) can be seen looking demure on a British bank note-a most respectable place to have one's portrait displayed. She is known today as the founder of modern nursing, but is ignored as a healthcare research methodologist of the highest skill. She was a "passionate statistician", responsible for the most remarkable hospital quality improvement project ever carried out and, as shown by her careful quantitative documentation, of both the process and outcomes of care.

The central event of her life was her care improvements at Scutari Hospital in Turkey during the Crimean War of 1854-6. In this unnecessary but popular war the British, with their French and Turkish allies, fought the Russians to a standstill on the Crimean peninsula on the north shore of the Black Sea. The incompetence of the British generals is remembered today through the bravery and folly of the "The charge of the Light Brigade". Leo Tolstoy wrote of even worse muddle on the Russian side.

British soldiers wounded on the Crimean battlefields were put on transport ships and taken across the Black Sea primarily to Scutari Hospital near Constantinople/Istanbul. When they landed there they were still in the uniforms they wore on the battlefield when they were wounded. In the hospital they faced dirty beds, clogged latrines, bad food, filth, and death. Overcoming the hostility from the British military hierarchy, Nightingale and her 40 nurses cleaned up this pestilential mess.

In her detailed statistical report she said the causes of the Scutari mortality were fivefold: frightful overcrowding, want of ventilation, drainage, cleanliness, and hospital comforts. She quantified and measured these problems and remedies. To measure overcrowding she documented the amount of space per patient in London hospitals at about 1600 square feet compared with 300-500 square feet at Scutari. Windows were opened for the first time and drains were cleaned out. For example, in the week of 14 April 1855, 215 handcarts of filth were removed, the sewers were flushed 19 times and the carcasses of two horses, a cow and four dogs were buried. The soldiers brought their blankets from the Crimea "unavoidably covered with vermin". Nightingale counted the thousands of items of clothing washed. Hospital comforts included a lack of eating utensils which she supplied.

She recorded the outcomes of care. The death rate among the patients was worst in February 1855 at $42.7 \%$ of all soldiers admitted. After her sanitary reforms, which started on 17 March 1855, the death rate fell to $2.2 \%$ by June 1855 . She showed a causal link between the sanitary reforms and this dramatic fall in mortality. You would think that this evidence would have been sufficient to convince everyone. Of course not. The Principal Medical Officer of the Army said it was due to the improved character of the cases coming from the Crimean peninsula-in short, severity of illness could explain away these differences. To rebut this argument Nightingale showed that the deaths were due not to battlefield wounds, but from what today we would call infectious diseases. She reported that the hospital's unsanitary environment led to the deaths of both wounded soldiers and healthy unwounded orderlies working there.

In addition to these before and after outcome measures linked to process reforms, Nightingale found two concurrent control groups. Her genius led her not to pick similar control groups but to choose them purposely to be non-comparable in that their differences were biased against her hypotheses. To show how bad Scutari was at its worst, she found a sicker group of soldiers. To show how healthy Scutari and the soldiers in the Crimea became, she found a presumably healthier group.

For the first comparison she chose soldiers too badly wounded on the battlefield to be put on the transport ships and who were cared for in the Crimea. These soldiers, too sick to move, had a mortality rate of 27 per 1000 compared with 427 deaths per 1000 at Scutari at the same time. To demonstrate the results of the improvements, she compared the mortality at Scutari with the best hospitals in London and the military hospitals there where the mortality rate was higher than the $2.2 \%$ rate at Scutari. She went on to show that the death rate of all British soldiers in England was higher than those in the Crimea by the end of the war and after her reforms. This observation became the basis for her call for health reforms for the entire British army. The inadequacy of the army's healthcare data analysis led Nightingale to call for "the absolute necessity of a statistical department". Her reform efforts continued throughout her long life.

There are many reasons for her success. She had the technical and professional knowledge, knew what she wanted to do, and did it with a constancy of purpose lasting decades. This was the first war with fulltime newspaper reporters. Their reports to the British public made Nightingale a heroine and helped raise essential funds for her use, independent of the military. When she returned to England, instead of accepting public applause in London she went to visit Queen Victoria in Scotland. The power of these two women, the public media, determination, and appropriate statistics explain Nightingale's ultimate success over a rigid military bureaucracy.

\section{WHERE TO LEARN MORE}

Nightingale threatened to publicly distribute her 1858 statistical report "Notes on Matters Affecting the Health, Efficiency and Hospital Administration of the British Army Founded Chiefly on the Experiences of the Late War" unless the government appointed a Royal Commission empowered to make improvements. The Commission was created and these Notes were never distributed. Today it is a very rare and ignored book. A large part of it has been republished in "Florence Nightingale: Measuring Hospital Care Outcomes" by the Joint Commission on Accreditation of Healthcare Organizations, Oakbrook Terrace, Illinois in 1999. In addition to several well known biographies by writers uninterested in statistics, see:

- Vicinus M, Nergard B, eds. Ever Yours, Florence Nightingale, Selected Letters. Cambridge, MA: Harvard University Press, 1990.

- Goldie S, ed. "I Have Done My Duty": Florence Nightingale in the Crimean War 1854-1856. Iowa City: University of Iowa Press, 1987.

D Neuhauser, Professor of Management, The Charles Elton Blanchard School of Medicine, Case Western Reserve University, 10900 Euclid Avenue, Cleveland, OH 44106-4945, USA; drn@cwru.edu 